\title{
Nature and Culture
}

$\mathrm{A}$ recent article in Conservation Biology should be a heads up for restorationists who are interested in thinking clearly about the nature of their work, or who care about the ways in which that work is construed by others.

The article, written by the University of North Texas environmental philosopher J. Baird Callicott and colleagues Larry B. Crowder at Duke University and Karen Mumford at the University of Minnesota, is titled "Current Normative Concepts in Conservation" (Conservation Biology, 13(1): 22-35, February 1999). In it the authors suggest that various schools of thinking about the environment and conservation can be interpreted in terms of two new schools of conservation philosophy, which they identify as "compositionalism" and "functionalism." These categories correspond pretty closely to community ecology on the one hand, and ecosystem ecology on the other. Thus "compositionalists" tend to think about landscapes and their conservation mainly in terms of species and populations, while "functionalists" tend to think about it primarily in terms of, well, function.

So far, so good. But this is not all. Compositionalists and functionalists not only look at landscapes in different ways, Callicott and his colleagues argue, they also think differently about nature and about the relationship between humans and the rest of nature.

Briefly, they argue that functionalists tend to think of humans as a part of nature, while compositionalists tend to think of humans as separate from nature. And-this is the kicker-they place ecological restorationists directly in the compositionalist school, along with others who assume that humans and human culture exist somehow outside of nature.

This may come as a surprise to restorationists who have learned to think of their craft not only as a way of achieving intimacy with a "natural" landscape, but also as a way of affirming the naturalness of humans by providing them with a role in the ecology of "natural" ecosystems.

Nevertheless, a characterization of this kind, appearing in a leading international journal, demands attention, and perhaps even calls for a bit of self-examination. Is that what restoration is really about-re-creating landscapes that are defined as "natural" because they reflect little or no human influence, and in the process asserting the un-naturalness of our own species? Is that really how restorationists think about their work? And if it isn't, then why do scholars outside the field get the impression that it is? Is this simply misinterpretation? Or are they, as often happens, seeing us more clearly than we see ourselves?

Reflecting on these questions, I have come up with a number of observations.
First, Callicott and his colleagues build their argument on two definitions of "restoration," implying that these accurately reflect the way restorationists think about their work. The first is the definition published by the Society for Ecological Restoration in 1997: " ... the process of returning, as nearly as possible, a biotic community to a condition of biological integrity."

The second, from a 1994 paper by Paul Angermeier at Virginia Polytechnic Institute and Jim Karr at the University of Washington, asserts that "the goal of ecological restoration is to produce a self-sustaining system as similar as possible to the native biota."

In their paper, Callicott and his colleagues present these two definitions back to back, as though they are interchangeable, or at any rate essentially in agreement. But it seems to me that they are actually quite different, particularly with respect to the definition of goals for restoration projects and the idea of nature they imply.

Angermeier and Karr's definition clearly implies that restoration entails a return to some more "natural" condition, characterized by a "native" biota, and of course this leads to the arguments about what is native (or "natural") and what isn'targuments that we have all been involved in and that never seem to come to an end.

SER's definition, on the other hand, doesn't mention "nature" or "native" species, but only "biological integrity." It is difficult to understand how this reflects a philosophy that sets culture apart from nature. And it is difficult to understand how this supports the idea that "compositionalists tend either to ignore the presence of Homo sapiens in the Americas or to treat such peoples as wildlife" (page 26).

Quite the contrary, it has always seemed to me that, through the rediscovery and reenactment of historic technologies such as burning, North American and Australian restorationists have played a leading role in discovering the integral role of pre-contact peoples in the landscape, even when this has meant, as it sometimes has, disagreeing with those who insist on the environmental innocence or ecological neutrality of people living in traditional cultures.

Besides this, it is worth pointing out that Callicott and his colleagues depend heavily on a single paper by two academic scientists to establish their characterization of restoration. Though they quote SER's definition, they don't really build on it, and, as I have pointed out, it doesn't actually support their case. (In fact, it represents an exhaustive, decade-long effort by restoration practitioners to define their work in a way that avoids precisely this kind of misreading of what restoration is and how restorationists think about it.) The problem here, I suspect, is the scholar's habit of relying on printed sources of information, 
which, in a field like restoration, means that the scholar simply is not in touch with the largely non-academic, essentially oral culture that is generating much of the information and most of the new ideas.

Having said that, however, I have to admit that it is not hard to understand why this characterization of restoration and the way restorationists think about restoration finds its way into the pages of a prestigious scholarly journal.

The truth is that, despite the avoidance of the nature/culture duality in a carefully crafted statement like SER's definition of "restoration," many restorationists actually do think and talk about their work as the restoration of "nature" in some privileged or special sense.

At least part of the reason for this is obvious. Though, as the work of a few young historians like Marc Hall and Tamara Whited is making clear, the idea of restoration dates back many centuries; in New World contexts-principally North American and Australia-this old idea took on a distinctive form. An Old World practitioner-a monk in 14th century France, for example, or a forester in 19th century Italy-clearly understood that what he was restoring or maintaining were attributes of an historic landscape. But in the New World the situation was different. Here the cultural disjuncture caused by the European invasion fostered the illusion that the pre-contact landscape was pristine, a landscape that represented nature in its pure form, uncompromised by culture. And of course it was this pre-contact landscape that became both the inspiration and the primary model for the New World conservationists who eventually applied the word "restoration" to their work.

Nature, Mike Soulé once said, is whatever you knew when you were six years old. I would say that it is whatever was here when you arrived. So it is not surprising that the conservationists who began trying to re-create prairies and other pre-contact landscapes early in the 20th century thought of what they were doing as the re-creation of nature.

This, I suspect, is the idea, or aspiration, or myth that lies behind the New World version of the idea of restoration. One great value of restoration, however, is that it takes the myth seriously enough to attempt to reduce it to practice. And in the process it both deconstructs the original, naive myth of an "original," Edenic landscape and generates a less sentimental, more powerful myth - a myth of rebirth and regeneration.
Thus, in her search for the primal Eden, the restorationist discovers ... history. The prairies our grandparents idealized as pristine and "natural" turn out to be partly anthropogenic and in this sense not fundamentally different from a medieval mowing meadow or an ancient forest in Mexico or Oregon or British Columbia that reflects millennia of human management and influence.

What this suggests is a better way of thinking about restoration. Don't think about it as the restoration of "nature." Think of it rather as the re-creation of an historic landscape- conceived, of course, in dynamic terms. Or think of it as a dialogue with nature-as-given - that is, the nature that we merely encounter or discover and that owes nothing to "us," whether by "us" we mean ourselves personally, our community, our society, our civilization or even our species.

All of these presences or arrivals represent thresholds in the evolution of a people, a landscape and its resident consciousness that are important and worthy of the restorationist's attention. All of them offer interesting goals for restoration projects, all of which provide opportunities to explore "our" influence on a landscape, and in the process to discover who "we" are in ecological terms.

This works as well in an Old World as in a New World landscape, resolving a disjuncture that often complicates conversations between restorationists from different parts of the world. And it disposes of the idea of re-creating "nature" conceived as in any way a different kind of thing than culture.

The value of restoration is not that it restores "nature," or even that it restores the health or integrity of an ecosystem (though sometimes it does that). Its value is that it entails a highly reflexive attempt to act neutrally toward the rest of nature, avoiding the value judgements implicit in terms like "health" or "integrity" or even "nature." Seen this way, the attempt to reproduce a landscape or ecosystem has value precisely because it is an occasion for seeing the world clearly and, to the extent possible, neutrally — seeing what is really there.

It is impossible to do this perfectly, of course. But trying to do it has value in itself. It is the best way there is to ensure the survival of an historic —or classic - landscape like a tallgrass prairie, an alpine meadow, or an olive grove. And it provides a context for a dialogue with our own history and with nature as given that is the key to defining who we are and where we fit in.

William R. Jordan III 